\section{The Efficiency of Railways Specialized in Transporting Iron Ore and Pellets}

\author{
Eficiência das Ferrovias Especializadas em Transporte de Minério de Ferro \\ e Pelotas
}

\author{
Renata G. de Oliveira Fontan ${ }^{10}$ \\ Rodrigo Alvarenga Rosa ${ }^{1}$ (อ \\ Adonai José Lacruz*2,3
}

\section{ABSTRACT}

Objective: the objective is to compare the relative efficiency of the railways specialized in transporting iron ore (MFe) and pellets (PLMFe), which are part of the assets of mining companies and pellet plants considering the 2016 scenario. Methods: the methods used were the data envelopment analysis (DEA) technique, with the application of the output-oriented constant returns scale (CRS) model; the initial combinatorial multicriteria method for choosing the input variables; and Tobit regression as a validation strategy for the DEA model. Results: of the twelve railways evaluated, three railways were identified as efficient: Estrada de Ferro Carajás, Fortescue, and Mount Newman. Conclusions: the applied model was considered a good method to evaluate the efficiency of railways specialized in transporting MFe and $\mathrm{PLMFe}$, as it determined the efficiency of each railway, suggesting the necessary increase in the output variable or adjustments in the input variables so that the railways reach the efficiency frontier. With that, companies can use the results of this study to guide future improvements to make their railways more efficient or maintain them on the frontier of efficiency.

Keywords: railways specialized in iron ore and pellets; data envelopment analysis; rail freight transport efficiency.

\footnotetext{
* Corresponding Author.

1. Universidade Federal do Espírito Santo, Programa de Pós-graduação em Engenharia Civil, Vitória, ES, Brazil. 2. Universidade Federal do Espírito Santo, Programa de Pós-graduação em Administração, Vitória, ES, Brazil. 3. Instituto Federal do Espírito Santo, Viana, ES, Brazil.

Cite as: Fontan, R. G. de O., Rosa, R. A., \& Lacruz, A. J. (2022). The efficiency of railways specialized in transporting iron ore and pellets. Revista de Administração Contemporânea, 26(1), e200284.

https://doi.org/10.1590/1982-7849rac2022200284.en
}

\begin{tabular}{|c|c|c|c|c|c|c|c|c|c|}
\hline & 1 & 2 & 3 & 4 & 5 & 6 & 7 & 8 & 9 \\
\hline $1^{\text {st }}$ round & (x) & & $\stackrel{9}{2}$ & $\stackrel{0}{2}$ & & & & & \\
\hline $2^{\text {nd }}$ round & $\stackrel{0}{\circ}$ & 2 & $\stackrel{9}{2}$ & & & & & & \\
\hline $3^{\text {rd }}$ round & (x) & $\stackrel{9}{2}$ & & & & & & & \\
\hline
\end{tabular}

Objetivo: objetiva-se comparar a eficiência relativa das ferrovias especializadas em transporte de minério de ferro (MFe) e pelota (PLMFe), que fazem parte do patrimônio das empresas de mineração e usinas de pelotizaçáo considerando o cenário de 2016. Métodos: foi utilizada a técnica análise envoltória de dados (DEA), com aplicação do modelo de retornos constantes de escala (CCR) e orientaçáo à saída (output); o método multicritério combinatório inicial para escolha das variáveis de entrada e a regressão Tobit como estratégia de validação do modelo DEA. Resultados: das doze ferrovias avaliadas, três ferrovias foram identificadas como eficientes: Estrada de Ferro Carajás, Fortescue e Mount Newman. Conclusóes: o modelo aplicado foi considerado como um bom método para avaliar a eficiência das ferrovias especializadas em transporte de MFe e PLMFe, pois determinou a eficiência de cada ferrovia, sugerindo o aumento necessário na variável de saída ou ajustes nas variáveis de entrada para que as ferrovias atinjam a fronteira de eficiência. Com isso, as empresas podem utilizar os resultados deste estudo para guiar melhorias futuras para tornar suas ferrovias mais eficientes ou se manter na fronteira de eficiência.

Palavras-chave: ferrovias especializadas em minério de ferro e pelotas; análise envoltória de dados; eficiência do transporte ferroviário de carga.

JEL Code: L7.

Editor-in-chief: Wesley Mendes-Da-Silva (Fundação Getulio Vargas, EAESP, Brazil) (t) Associate Editor: Paulo César Matui (Unigranrio, Brazill) Reviewers: Fernando Augusto Silva Marins (Universidade Estadual Paulista, Brazil) Rafael Carvalho Miranda (Universidade Federal de Itajubá, IEPG, Brazil) (1) One of the reviewers chose not to disclose his/her identity. Peer Review Report: The Peer Review Report is available at this external URL. Received: August 03, 2020 Last version received: March 15, 202 Accepted: April 09, 2021 


\section{INTRODUCTION}

This technological article (Motta, 2017) is oriented to practitioners and to those interested in studying the efficiency of railways specialized in transporting iron ore $(\mathrm{MFe})$ and pellets (PLMFe) and/or the data envelopment analysis method (DEA).

Objectively, this study evaluates the relative efficiency of the railways specialized in transporting $\mathrm{MFe}$ and PLMFe, which are part of mining companies' and pelletizing plants' heritage, using the DEA technique. It is clarified that the data collected in 2018 reflect the scenario of 2016 .

The MFe is a mineral found in nature in the form of rocks mixed with other elements. Through beneficiation processes, it is obtained in granularity and amount of iron content ideal to be sold to the steel industries. The PLMFe is a cluster of MFe in a spherical shape, obtained through an industrial process, taking advantage of the fines generated during the ore extraction, which were discarded. Both MFe and PLMFe are fundamental to the global economy as they are inputs for steelmaking.

In this market, companies, as a rule, decide to establish their own logistics chain, thus needing to build their transport infrastructure to transport the production of MFe and PLMFe. Rail/train transport is a means of transportation that best meets the volume handled by these companies.

Railways specialized in the transport of MFe and PLMFe have these as predominant products in their transported cargo matrix. These two loads can be treated similarly for three reasons: both have a specific weight close to $2.22 \mathrm{ton} / \mathrm{m}^{3}$; use the same type of wagon; and MFe's and PLMFe's loading, transporting, and unloading operations are similar.

Some characteristics that differentiate this type of railway from others are the weight of the cargo transported by wagon, with a high load value per axle, requiring more of its locomotives and wagons. In addition, on these railways, as a rule, many trains run daily, causing a greater level of degradation on the railroad due to the increase in train traffic and the train size, which is more extensive and has more locomotives and wagons in their formation than trains carrying different types of cargo.

Besides, as they are the property of mining companies and/or pellet plants, they do not charge freight for transportation and are seen as a cost center for the mine and/or the plant's operation. However, the railway mode requires significant investments and has high operating costs, significantly affecting the final product value.
In line with the market and competitiveness strategy, companies seek to increase rail transport efficiency to reduce costs.

Considering that the railroads transport similar products, the comparison will make it possible to understand why one railroad is more efficient. Hence, this article's objective is to evaluate the efficiency between these railways specialized in the transport of MFe and PLMFe using the DEA technique to measure and compare their efficiency, identifying which railways are considered efficient and how far the others are distant from this reference. Therefore, having relative performance as the outcome, it is possible to know measures that can be taken to make the railroad more efficient.

The DEA model chosen for the application was the constant returns to scale or CCR model - in homage to its authors Charnes, Cooper and Rhodes (1978) with output orientation. The CCR model applies a linear function to analyze efficiency, characterized by the best ratio of the proportion of the output variables to the input variables of a given unit observed, also known as decisionmaking units (DMUs). Thus, the object of study of this article is the 12 railroads specialized in the transport of MFe and PLMFe worldwide, which are part of the heritage of large mining and/or pelletizing companies, considered as DMUs.

As input variables, representing inputs, have been adopted: the number of ore cars in operation (VAG), axle load (CGE), and the number of wagons of the most predominant type of train (TTP). The useful tonkilometer (TKU) indicator was adopted as an output variable, expressing the useful ton transported by the distance covered. It is clarified that for the selection of the variables, the initial combinatorial multicriteria method was used. Moreover, the tobit regression was used as a strategy for validating the efficiency model.

The data for the year 2016, collected in 2018, reflect four of the five significant events that changed the dynamics of the market, namely: entry of the new player Fortescue; retraction of the Chinese market and a sharp fall in the prices of MFe; disruption of Samarco's dam; and the start of production at Vale's S11D mine. With the release of the 2016 results by the companies, the railway data were collected.

This article is justified because it differs from the others published on DEA and railroad since it deals with the analysis of MFe and PLMFe transport railways that are part of the heritage of mining companies and/or pelletizing plants and, therefore, do not charge freight for the transportation of MFe and PLMFe, being treated as cost centers by the companies mentioned above. They also 
differ because they operate with longer trains, with more wagons, and heavier wagons (greater weight per axle). In addition, companies have autonomy in decision-making to increase efficiency and reduce costs.

This article contributes to the managerial practice by presenting the efficiency frontier and, consequently, the efficient railways in applying resources and the actions that companies can take to improve their efficiency index and consequently increase their competitiveness.

\section{EMPIRICAL CONTEXT}

The MFe and PLMFe (pellet made of agglomerate of MFe fines generated during the extraction of $\mathrm{MFe}$ ) are critical to the global economy since they are inputs for steelmaking, with significant demand in the automotive, machinery, and construction sectors.

Consultation carried out in 2020 on the Statista website about the 2016 scenario shows that 2.34 billion tons of MFe were produced worldwide, led by Australia with a production of 825 million tons approximately, which is equivalent to $34 \%$ of the global scenario. Second in the ranking is Brazil, which produced in 2016 around 391 million tons, representing $16 \%$ of the world production, followed by China, with 353 million tons, responsible for $14 \%$ of the world production (Garside, 2020). In the last few years, five major events have changed the dynamics of the iron ore market and interfered with how miners/ pelletizing plants operate. In 2014, Fortescue emerged, a new Australian competitor with an expressive production of 165 million tons per year (Mta) of MFe, assuming a space in the market that caused the loss of market share of competitors. In 2015, with the reduction in demand from China, the market reacted with a significant drop in the price of $\mathrm{MFe}$, which caused cancellations and/ or postponements of several expansion projects of $\mathrm{MFe}$ mines. At the end of 2015 was the breaking of the dam of the Samarco tailings company, withdrawing a significant volume of pellets from the market as a result. In 2016, production began at Vale's S11D mine, making it possible to offer over 90 million tons of high-quality MFe a year. Besides, at the beginning of 2019, Vale's tailings dam broke down in the city of Brumadinho, interdicting several operations of this company, reducing the MFe's and PLMFe's supply, and unbalancing the market again. In the face of the constant changes in market valuation and volatility in the price of MFe and PLMFe, all mining companies and pellet producers sought ways to reduce costs and increase productivity to improve their competitiveness in such a dynamic market.
There are 12 railroads in the world specialized in the transport of MFe and PLMFe; they are part of the heritage of large mining and/or pelletizing companies, five of which are Anglo-Australian (one from BHP Billiton, two from Rio Tinto, one from Fortescue, and one from Roy Hill), two Brazilians from Vale, two Canadians (one from Rio Tinto and one from Arcelor Mittal), one from LKAB, and two from Africa (one from Arcelor Mittal and one from SNIM).

This choice was made because these companies have the autonomy to implement actions that can improve the performance of their rail transport. The railroads that are service providers were disregarded, in which the miners pay tariffs for the transportation of their products and do not have autonomy for operational modifications; among these, the present research cites MRS Logística S/A in Brazil.

In a competitive scenario, in search of cost reduction and gain in productivity, the following questions arise: Which railroads specialized in the transportation of MFe and PLMFe in the global scenario were efficient in applying resources in the year 2016? What are the points of inefficiency that deserve attention?

These questions address the applied objective of demonstrating the application of the DEA methodology to deal with this problematization.

\section{DATA ENVELOPMENT ANALYSIS AND RAILROAD EFFICIENCY}

Charnes et al. (1978) initially developed the DEA method and used linear programming to calculate the efficiency of observed units, called decision-making units (DMUs). A DMU can be defined as a company or an organizational division of the company in which its efficiency is evaluated. The purpose of applying the DEA methodology is to compare the chosen DMU that perform similar activities. From this, it is verified which DMUs are at the efficiency frontier, with an efficiency index equal to one. Railways that have an efficiency rating below one are not considered efficient.

Two models represent the DEA methodology: Charnes, Cooper, and Rhodes (CCR) and Banker, Charnes, and Cooper (BCC). The CCR calculates efficiency by a linear function, characterized by the best ratio of the proportion of the outputs to the inputs of a given DMU. A characteristic of the CCR concerns orientation, whether it is input or output, which does not influence the efficiency value because this model works with the proportional variation between inputs and outputs. So the choice is based on the goal you want to achieve: reducing the use of 
inputs or increasing outputs (Cinca, Molinero, \& Callén, 2016).

The BCC was proposed after the CCR and considers scale returns, replacing the theory of proportionality between inputs and outputs with the theory of convexity. The most significant difference of BCC was the introduction of the concept of variable return of scale, with the addition of the variable that represents the scale factor (Reis, Sacramento, Mello, \& Meza, 2017). The main feature of the BCC model is that the efficiency frontier is limited to the convex combinations of the observed production plans, while in the CCR the efficiency frontier is a straight line with a 45-degree inclination (Bogetoft \& Otto, 2011).

In addition to measuring efficiency, the DEA method offers data on inefficiency, showing input or output variables that were used unsatisfactorily and have gaps that could be eliminated (Lin \& Tseng, 2007). The DEA model may have two different orientations indicating how a DMU reaches the efficiency frontier: (a) input orientation and (b) output orientation. The first seeks to answer the proposition of what is the possible amount of proportional reduction of inputs without changing the outputs produced. On the other hand, the second indicates the possible amount of proportional increase of the output, without changing the quantities of input, i.e., it seeks to obtain the best result by applying a certain level of resource (Caldas, Gabriele, Carvalhal, \& Ramos, 2012).

The following is the literature review, based on the search for the following keywords: benchmarking, railroad, railway, efficiency, efficiency DEA, data envelopment analysis, cargo and freight transport. The search was based on the following websites: Capes journals, Science Direct, Scopus, and Google Scholar.

Yu (2008) evaluated 40 European railways and determined three performance measures for the railways: technical efficiency, service efficiency, and technical efficiency to help companies improve the performance of their railways. Asmild, Holvad, Hougaard and Kronborg (2009) estimated the inefficiency in each portion of the railway cost (infrastructure, equipment, maintenance, personnel, etc.) separately, investigating the impact of European railway reforms on the costs of the operation.

Cantos, Pastor and Serrano (2012) evaluated, using DEA, 23 European railways from 2001 to 2008 to estimate the evolution of efficiency levels after regulation and restructuring of rail transport in Europe. The results show that competition in the cargo and passenger transport sectors positively affected both efficiency and productivity.
Kutlar, Kabasakal and Sarikaya (2013) measured the performance of freight and passenger railway companies worldwide, from 2000 to 2009. They used DEA CCR and BCC. They pointed out that DEA allows evaluating many variables (both input and output) simultaneously, useful for real applications. Pereira, Rosa and Lunkes (2015) evaluated, using DEA, the efficiency of railway concessionaires in Brazil from 2009 to 2013, with a financial bias, evaluating expenses as input and revenue as output. Of the eleven railways analyzed, four showed maximum efficiency in the five years examined.

Sharma, Debnath, Oloruntoba and Sharma (2016) consider that the choice by DEA to the stochastic frontier analysis (SFA) methodology was made because SFA takes on a preconceived functional form of the production frontier. In contrast, the DEA approach uses linear programming to build the production frontier, which involves all units of measurement (DMU). Reis, Sacramento, Mello and Meza (2017) used DEA BCC output to calculate the efficiency of twelve Brazilian freight transport railways. The results showed five efficient railroads. The authors did not reach a conclusion on the reasons that influenced the railroads to reach efficiency.

Marchetti and Wanke (2017) evaluated the efficiency of twelve Brazilian railroads between 2010 and 2014 when new competitive regulations were introduced in Brazil. DEA BCC and CCR models were used to identify efficiency. The authors found that sharing infrastructure with more than one operator did not influence the performance of the DMU.

Zhou and Hu (2017) used DEA BCC in two stages (production and service) to calculate the overall sustainability performance and substation of rail transport in China from 2002 to 2013, from aspects of economy, environment, and society. Wanke, Chen, Liu, Antunes and Azad (2018) investigated the drivers of railway performance in Asian countries in view that the publications focus more on measuring efficiency and less on discussing actions for possible improvements.

Silva, Oliveira and Marinov (2020) evaluated the impact on the efficiency of cargo transportation in four Brazilian railway companies after the vertical merger that formed the company RUMO-ALL. Data from 2006 to 2018 were considered using the DEA CCR input. For the authors, the main operational issues that can limit or increase the productivity of the railroads are the size of the train, time of dispatch of the trains, weight loaded in each wagon, operational availability of the locomotives and wagons, and speed of the track. The result pointed to a significant efficiency change in two railroads, suggesting prioritizing heavy cargo transport. 
In this literature review, no publication was found that dealt only with railroads owned by mining companies/MFe and PLMFe plants, which differ from the others, mainly because they do not charge freight and have operational characteristics that are different from other types of railways, so much so that they are called heavy haul railways for their longer trains, with wagons with a higher ton per axle.

The model used for this article was DEA CCR output. The orientation was defined according to the choice of reducing inputs (input variables) without changing the quantities produced (output variables) or increasing the quantity produced (output variables) with the existing inputs (input variables). For this study, input orientation (input) was evaluated as impractical because it minimizes the railroad resources that lead to loss of scale in transport or reduced capacity of the assets, leaving a company vulnerable when moving to higher demand $\mathrm{MFe}$ and PLMFe markets. Such measures on the railway may result in a loss of competitiveness if the company's response time is slow, losing ground. Accordingly, it makes more sense to work with the output orientation, i.e., increase the total MFe and PLMFe transported by railroad.

Against this background, which is a more restricted business segment, and considering the particularities of the railroad, the CCR model was the most appropriate to solve the proposed problem. The CCR model works with the proportionality relationship between inputs and outputs, which is best applied in assessing the application of resources (VAG, CGE, and TTP) in obtaining the volume moved by the distance traveled (TKU). However, these results are conditioned to the set of values of the railroads presented. Furthermore, if any variable or the amount of DMUs (inclusion or exclusion) changes, the result is a relative efficiency.

\section{Application of data envelopment analysis}

In this article, the output-oriented DEA CCR method was used. The CCR model is presented in the following model, and its objective function is presented in Equation 1, where $E_{f f 0}$ is the efficiency of $\mathrm{DMU}_{0}$ under analysis; $x_{i 0}$ : input $i$ of $\mathrm{DMU}_{0} ; y_{j 0}$ : output of $\mathrm{DMU}_{0}$; $x_{i k}$ : input $i$ of DMU $k, k=1, \ldots, n ; y_{j k}$ : output $j$ of DMU $k, k=1, \ldots, n$; $v_{i}$ : weights of input $i, i=1, \ldots, r ; u_{j}$ : weights of the output $j, j=1, \ldots, s ; \mathrm{u}^{*}$ : scale factor.
Objective function:

Maximize $E_{f f 0}=\sum_{j=1}^{s} u_{j} y_{j 0}$

Subject to:

$\sum_{i=1}^{r} v_{i} x_{i 0}=1$

$\sum_{j=1}^{s} u_{j} y_{j k}-\sum_{i=1}^{r} v_{i} x_{i k} \leq 0 \quad \forall k=1, \ldots, n$

$u_{j}, v_{i} \geq 0 \quad \forall i=1, \ldots, r, j=1, \ldots, s$

$u * \in R$

The CCR aims to determine the optimal weights $u_{j}$ (output variable) and $v_{i}$ (input variable). If the efficiency $E_{f f 0}$ is equal to one, it means that the DMU is efficient. If the result is less than one or equal to zero, the DMU is not considered efficient.

The DEA CCR model is based on the assumption of constant returns to scale, in which the growth of the input will produce balanced production/output growth; the measurement of the DEA CCR's efficiency is known as the technical efficiency (Marchetti \& Wanke, 2017).

The DMUs in this study are the railroads specialized in transporting MFe and PLMFe, which are part of the companies' assets (mining companies and/or pelletizing plants). Twelve railways were chosen, two Brazilian, two Canadian, five Australian, one Liberian, one Swedish, and one Mauritanian, as shown in Table 1. The railways that are service providers were disregarded, in which mining companies pay tariffs for the transportation of their products and do not have autonomy for operational modifications (e.g., MRS Logística S/A).

Subsequently, a survey of the possible (input and output) variables to be used is carried out. Based on the survey of studies presented in the theoretical framework and consultations with railway specialists, in Figure 1, the most relevant variables used in comparing efficiency between railways specialized in the transport of MFe and PLMFe were identified. 
Table 1. Railways defined as DMUs.

\begin{tabular}{lllll}
\hline DMU & Railroad & Company & Country & Cargo \\
\hline 1 & Estrada de Ferro Vitória Minas (EFVM) & Vale & Brazil & MFe + PLMFe \\
2 & Estrada de Ferro Carajás (EFC) & Vale & Brazil & MFe \\
3 & Mount Newman Railway (NEWM) & BHP & Australia & MFe \\
\hline 4 & Hamersley Railway (RTHA) & Rio Tinto & Australia & MFe \\
5 & Robe River (RTRR) & Rio Tinto & Australia & MFe \\
6 & Fortescue Railway (FMG) & Fortescue & Australia & MFe \\
7 & Roy Hill Railway (RHILL) & Roy Hill & Australia & PLMFe \\
8 & QNS \& L (QNSL) & IOC & Canada & MFe + PLMFe \\
9 & Cartier (CART) & Arcelor Mittal & Liberia & MFe \\
10 & Yekepa-Buchanan Line (AML) & Arcelor Mittal & Sweden & MFe + PLMFe \\
11 & Iron Ore Line (IOL) & LKAB & Mauritania & MFe \\
\hline
\end{tabular}

Note. Source: Prepared by the authors.

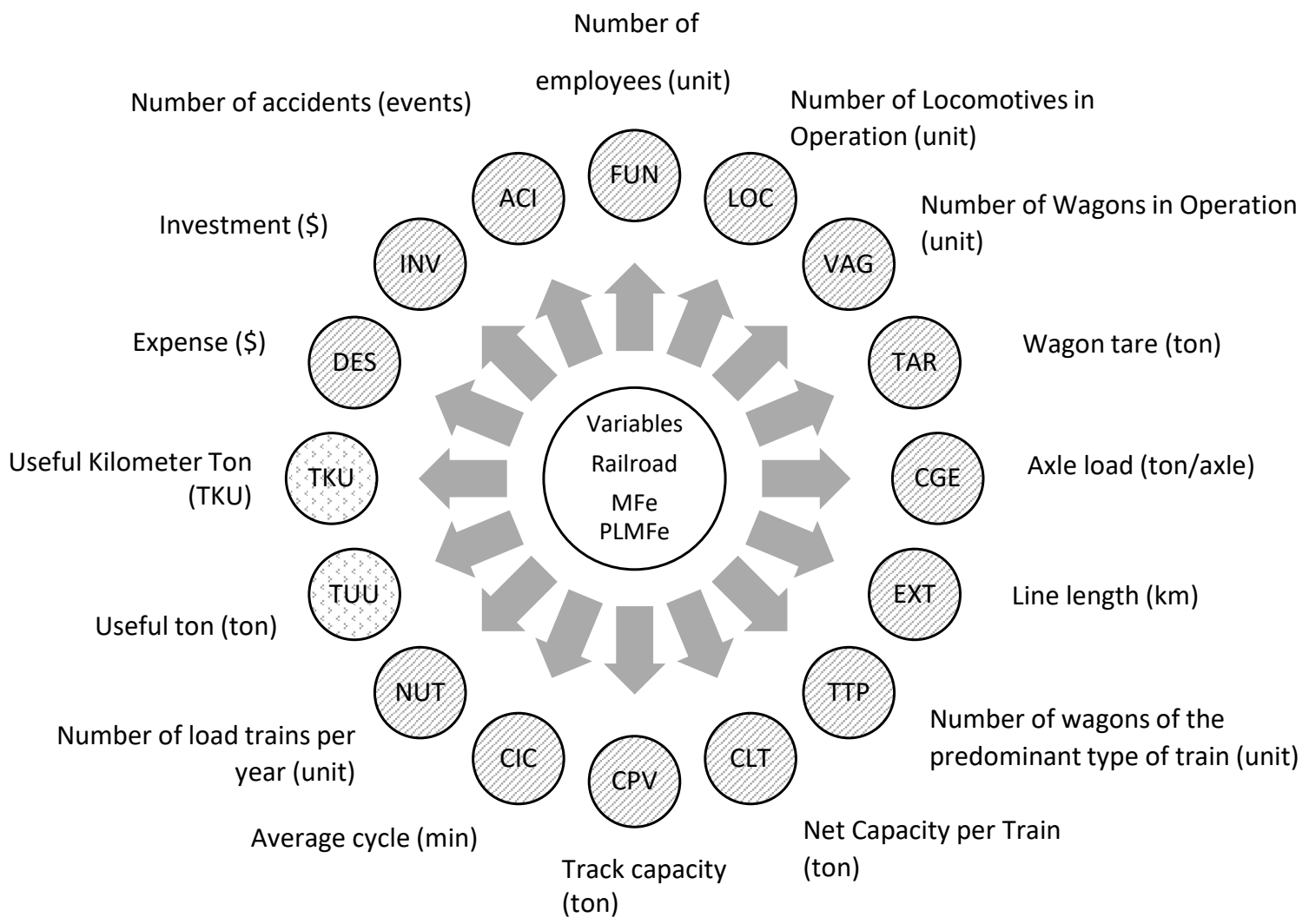

LEGEND: $\bigcirc$ Input variable $\bigcirc$ Output variable

Figure 1. Variables used to compare railroads. 
In this article, the input orientation was evaluated as impractical as it minimizes railroad resources, which leads to loss of scale in transport or reduction of railway capacity. This can leave a company vulnerable in the event of worldwide increased demand for MFe and PLMFe, making it impossible to respond to this increase in demand quickly. For these reasons, it makes more sense to work with the output orientation, i.e., to increase the total $\mathrm{MFe}$ and PLMFe transported by railroad.

The biggest difficulty in collecting data was obtaining data from the railways, as they are private companies that disclose financial results but do not detail their operations' technical information. The data collected refer to the year 2016, and the primary sources for obtaining the information were the institutional reports of the companies that owned the railroads chosen as DMU and information from regulatory bodies for rail transport.

In the surveys, the values of the variables were obtained: line length (EXT), which corresponds to the length of the railway, which starts at the mine/plant and ends at the port or a discharge point; the number of wagons in operation (VAG); the number of locomotives in operation (LOC); the number of wagons of the most predominant type of train (TTP); and the wagon axle load (CGE), which is the amount of MFe and/or PLMFe that is transported by each wheel (axle), considering that the evaluated wagons have four wheels. The present research investigated what type of wagon is used by each company and its weight when it is empty, defining the wagon tare (TAR). The net capacity per train (CLT) was obtained employing a calculation, multiplying the value of the load per axle (CGE) by four (each wagon has four wheels or axles) and then subtracting the value of the car's tare (TAR). The value is multiplied by the number of wagons on each company's most predominant type of train (TTP). The other variables were: the number of load trains (composition of locomotives and wagons) per year (NUT) loaded with MFe and PLMFe that traveled the length of the railway over a year; the MFe's and PLMFe's useful volume in tons (TUU); and the useful ton-kilometer (TKU), which represents the useful ton transported multiplied by the distance traveled, in ton.km unit. With the data collected, a database was created in Table 2.

Table 2. DMU database.

\begin{tabular}{lrrrrrrrrrrr}
\hline \multicolumn{1}{c}{ DMU } & EXT $^{1}$ & \multicolumn{1}{c}{ VAG $^{2}$} & \multicolumn{1}{c}{ LOC $^{2}$} & TTP $^{3}$ & CGE $^{4}$ & TAR $^{5}$ & CLT $^{5}$ & NUT $^{2}$ & TUU $^{5}$ & TKU $^{6}$ \\
\hline EFVM & 895 & 11,925 & 325 & 252 & 27.5 & 18 & 23,310 & 4,406 & 103 & 91,917 \\
EFC & 997 & 18,135 & 289 & 330 & 32.5 & 20 & 36,300 & 4,080 & 148 & 147,656 \\
NEWM & 426 & 4,000 & 178 & 268 & 37.5 & 20 & 34,840 & 6,359 & 222 & 94,382 \\
RTHA & 328 & 6,971 & 116 & 236 & 40.0 & 21 & 32,922 & 7,146 & 235 & 77,161 \\
RTRR & 242 & 4,529 & 75 & 167 & 40.0 & 21 & 23,297 & 1,520 & 35 & 8,570 \\
FMG & 620 & 4,600 & 53 & 250 & 42.0 & 20 & 37,000 & 4,676 & 173 & 107,260 \\
RHILL & 344 & 1,196 & 21 & 232 & 45.0 & 22 & 36,749 & 599 & 22 & 7,568 \\
QNSL & 418 & 1,000 & 20 & 265 & 36.0 & 20 & 32,860 & 554 & 18 \\
CART & 420 & 1,340 & 30 & 200 & 30.0 & 18 & 20,400 & 1,225 & 25 & 10,608 \\
AML & 243 & 195 & 4 & 70 & 30.0 & 18 & 7,140 & 294 \\
IOL & 390 & 1,100 & 17 & 68 & 32.5 & 21 & 7,398 & 3,636 & 2 \\
MAUR & 704 & 1,200 & 31 & 210 & 30.0 & 20 & 21,000 & 790 \\
\hline
\end{tabular}

Note. Source: Prepared by the authors. Units of measurement: ${ }^{1}$ kilometer $(\mathrm{km}) ;{ }^{2}$ unit; ${ }^{3}$ number of wagons per train; ${ }^{4}$ tons per axle (ton/axle); ${ }^{5}$ tons (ton); ${ }^{6}$ million tons per kilometer (million ton.km).

Knowing the causal relationship between the variables makes it possible to explain how a given cause implies a specific effect. With the help of specialists in the field, together with Table 2, Figure 2 was created, which demonstrates this relationship through the arrows; the correlation coefficient between the variables addressed is also presented (calculated using the Stata software). Based on Figure 2, it is possible to verify the causality relationship between the variables raised to measure the efficiency of the railways specialized in the transportation of MFe and PLMFe, which are assets of mining companies and pelletizing plants. 


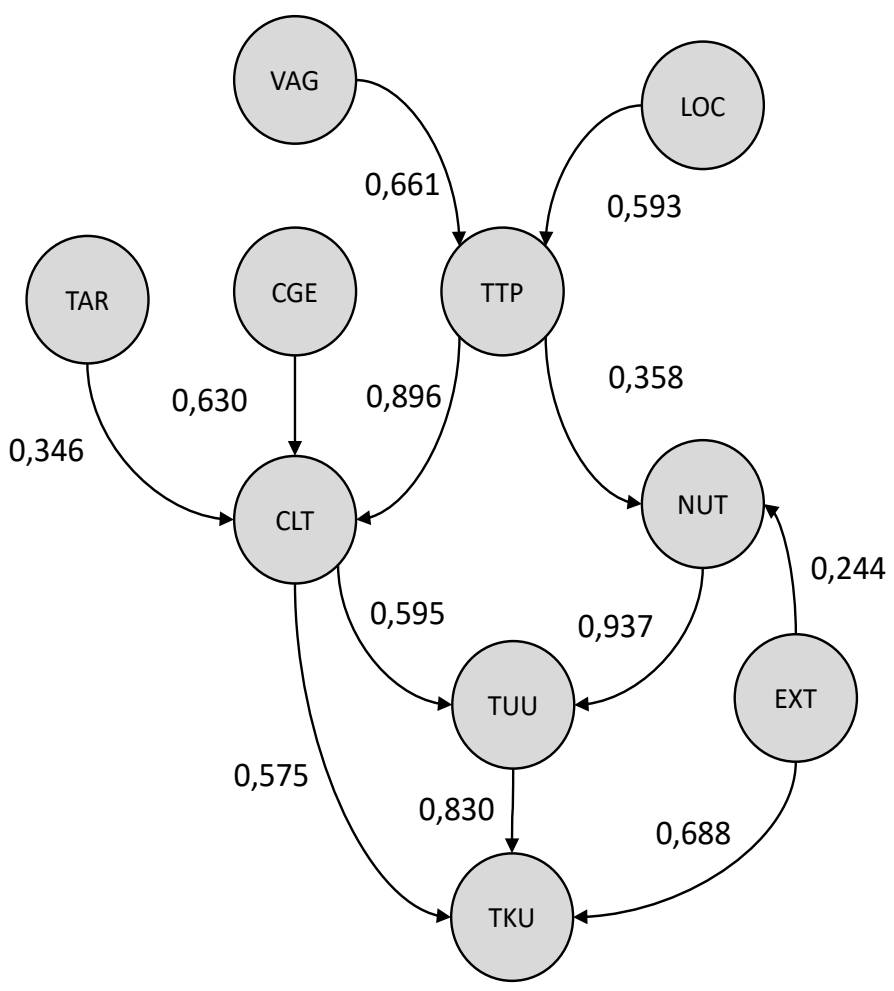

Figure 2. The causal relationship between variables.

In step with Miles and Shevlin's (2001) gradation, values between 0.10 and 0.29 , between 0.30 and 0.49 , and more significant than 0.50 are considered low, moderate, and high, respectively.

The DEA method has a limitation related to the number of variables used, to the point that if many variables are used with the amount of DMUs, there will be a tendency for many of these to be close to maximum efficiency, thus losing discretion. This problem can be avoided by restricting the number of variables used in the model. As this study has a limited amount of DMUs, which represents a specific business segment, the golden rule restriction was adopted (Banker, Charnes, Cooper, Swarts, \& Thomas, 1989), presented in Equation 6, in which $\mathrm{n}=$ number of sample observations, $\mathrm{p}=$ inputs, and $\mathrm{q}=$ outputs.

$\mathrm{n} \geq \operatorname{MAX}_{\{p \times q, 3(p+q)\}}$

It is noted that the DEA bootstrap (or smoothed bootstrap) approach, developed by Simar and Wilson (1998), corrects the upward bias of the DEA method when the sample size is inadequate for the number of entries and exits, i.e., the golden rule. However, as Chernick (2008) warns, the sample size must be at least 50 observations to estimate consistent, reliable scores using the DEA bootstrap.
Legend:

$\begin{aligned} \longrightarrow & =\text { Causal relationship } \\ \text { VAG } & =\text { Number of wagons in operation } \\ \text { LOC } & =\text { Number of locomotives in operation } \\ \text { TAR } & =\text { Tare of the wagon } \\ \text { CGE } & =\text { Axle load of the wagon } \\ \text { TTP } & =\text { Number of wagons of the predominant type of train } \\ \text { CLT } & =\text { Net capacity per train } \\ \text { NUT } & =\text { Number of load trains per year } \\ \text { TUU } & =\text { Useful ton } \\ \text { EXT } & =\text { Line length } \\ \text { TKU } & =\text { Useful ton-kilometer }\end{aligned}$

The selection of variables is the most critical part of developing the DEA model, for the choice of different sets of variables can lead to different analyses (Merkert, Smith, \& Nash, 2010). In many studies, this selection of variables is made according to the opinion of experts, which can lead to a biased result. Thus, to avoid this type of problem, the initial combinatorial multicriteria method was used to select the variables, as it does not depend on the decisionmaker's opinion (Senra, Nanci, Mello, \& Meza, 2007). This method is a variation of the multicriteria method of variables' selection (Mello, Gomes, Meza, \& Lins, 2004), characterized by a reasonable ordering of DMUs, being impartial in the choice of variables through a weighting between discriminatory capacity and efficiency model average.

However, before starting the selection method, a preliminary analysis of possible variables by experts and/ or decision-makers is essential to assess which variables contribute to the real purpose of the analysis, which contribute to the efficiency in the transport of MFe and PLMFe. With the help of six professionals in railway companies' operation, a previous selection of the variables to be associated with the TKU output was carried out, namely: VAG, LOC, CLT, TTP, and CGE. With this pre-selection, the input-output pairs were formed: VAG-TKU, LOCTKU, CLT-TKU, CGE-TKU, and TTP-TKU. 
The initial combinatorial multicriteria method weighs the results in terms of two criteria: (a) maximizing efficiency and (b) minimizing discrimination. Both criteria are calculated by Equation 1. The adjustment to the frontier is measured using average efficiency, which after normalization is called the $\mathrm{S}_{\mathrm{EF}}$ variable, assuming a value of 10 for maximum efficiency and zero for minimum efficiency. The minimization of discrimination is measured by the amount of DMUs that reached efficiency, which after normalization is called the variable $\mathrm{S}_{\text {DIS }}$, which assumes the value 10 for the lowest number of DMUs on the border and zero for the most significant number of DMUs that reached the border. The parameter $\omega$ allows assigning greater or lesser importance to each of the criteria according to the need for the analysis. However, because this study represents a specific segment of the MFe and PLMFe business, the technical experts concluded that it is more relevant to give notoriety to efficiency than to the amount of DMUs at the efficiency frontier, with a value of 0.6 being attributed to $\omega$. The initial calculation is made for each input-output pair and the one with the highest $S$ value, obtained by Equation 7, is incorporated into the model.

$S=\omega * S_{E F}+(1-\omega) * S_{D I S}$

Table 3 shows evidence that in the first round of the CCR output model, the TTP-TKU pair obtained the highest $S$ value, reaching the value equal to 1.00 ; hence, it was the first input-output pair chosen by the present research.

Table 3. The first round of the initial combinatorial multicriteria method for DEA CCR.

\begin{tabular}{|c|c|c|c|c|c|}
\hline \multirow[b]{2}{*}{ Input } & \multicolumn{5}{|c|}{ CCR Output Efficiency Index } \\
\hline & VAG & CLT & CGE & LOC & TTP \\
\hline Output & TKU & TKU & TKU & TKU & TKU \\
\hline EFVM & 0.3267 & 0.9694 & 0.7357 & 0.1397 & 0.8152 \\
\hline EFC & 0.3451 & 1.0000 & 1.0000 & 0.2525 & 1.0000 \\
\hline NEWM & 1.0000 & 0.6660 & 0.5540 & 0.2620 & 0.7871 \\
\hline RTRR & 0.0802 & 0.0904 & 0.0472 & 0.0563 & 0.1147 \\
\hline RTHA & 0.4691 & 0.5762 & 0.4246 & 0.3293 & 0.7307 \\
\hline FMG & 0.9882 & 0.7127 & 0.5621 & 1.0000 & 0.95589 \\
\hline RHILL & 0.2682 & 0.0506 & 0.0370 & 0.1781 & 0.0729 \\
\hline QNSL & 0.3224 & 0.0569 & 0.0465 & 0.1880 & 0.0642 \\
\hline CART & 0.3321 & 0.1265 & 0.0770 & 0.1729 & 0.1173 \\
\hline AML & 0.1109 & 0.0176 & 0.0037 & 0.0630 & 0.0163 \\
\hline IOL & 0.4042 & 0.3486 & 0.0711 & 0.3049 & 0.3448 \\
\hline MAUR & 0.4127 & 0.1368 & 0.0857 & 0.1863 & 0.1244 \\
\hline Average efficiency: & 0.4216 & 0.3960 & 0.3037 & 0.2611 & 0.4289 \\
\hline $\begin{array}{l}\text { Qty. DMU at the } \\
\text { frontier: }\end{array}$ & 1 & 1 & 1 & 1 & 1 \\
\hline$S_{\mathrm{EF}}:$ & 0.95 & 0.90 & 0.30 & 0.00 & 1.00 \\
\hline $\mathrm{S}_{\mathrm{DIS}}:$ & 1.00 & 1.00 & 1.00 & 1.00 & 1.00 \\
\hline$\omega:$ & 0.60 & 0.60 & 0.60 & 0.60 & 0.60 \\
\hline$S:$ & 0.97 & 0.94 & 0.58 & 0.40 & 1.00 \\
\hline
\end{tabular}

Note. Source: Prepared by the authors.

In the second round of the CCR output model, the input variables VAG, CGE, and LOC are incorporated separately into the TTP-TKU pair. The CLT variable was excluded because it had a strong correlation (0.896) with the TTP variable selected in the first round. Using
Equation 7 for the combinations made, the variable VAG was the second input variable selected to reach the highest value of $S, 0.60$.

The rounds are repeated until meeting the restriction on the number of variables per model of the DEA method. 
As this study adopted the golden rule restriction (Banker et al., 1989), the number of variables to be selected will be limited to four, which represents three rounds. The LOC variable was excluded in the third and last round because it had a strong correlation (0.906) with the VAG variable selected in the second round, leaving only the CGE variable to be selected.

As a conclusion of the initial combinatorial multicriteria method, for the CCR output model, three variables were selected as input variables (VAG, CGE, and TTP) and one as output variable (TKU).

\section{RESULTS}

This section discusses the results and analyses of the comparison of the railways specialized in transporting MFe and PLMFe, characterized by applying the DEA method. As seen in section "Data envelopment analysis and railroad efficiency", three input variables (VAG, CGE, and TTP) and one output variable (TKU) were adopted. Frontier Analyst software was used to run the DEA model.

Efficiencies were calculated, and those that achieved an efficiency index of one were considered efficient DMUs (railways). According to the CCR output model, there are three railways with an efficiency index of one, namely: EFC from Vale, NEWM from BHP, and FMG from Fortescue. According to the BCC output model, seven railways have an efficiency index of one, namely: EFVM and EFC from Vale; NEWM from BHP; FMG from Fortescue; AML from Arcelor Mittal; IOL from LKAB; and MAUR from
Mauritania. The others have an efficiency index below one and are not considered efficient.

Considering the particularities of the railroad, the CCR model proved to be more appropriate, for it works with the proportionality relationship between inputs and outputs, which is best applied in the application of resources' assessment (VAG, CGE, and TTP) in obtaining the volume handled by distance traveled (TKU).

Finally, as a strategy for validating the DEA model, tobit regression was processed, which deals with censored dependent variables; i.e., they are not freely distributed between $-\infty$ and $+\infty$ (Gujarati, 2000), as the efficiency index that emerges from DEA models.

Hence, the same variables of the developed DEA model (VAG, TTP, CGE, and TKU) were used as independent variables and the efficiency revealed in the application of DEA as a dependent variable. Additionally, a bootstrap resampling procedure (1,000 replications) was used. It is explained that the database was mirrored, as it was limited to 12 observations, and that the Stata software was used.

The results allow the validation of the applied DEA model since the coefficients of all variables were shown to be statistically significant ( $\mathrm{p}$-value $<0.05$ ), both in the original data (mirrored) and the bootstrap procedure.

Figure 3 presents graphically the efficiency indexes calculated using the CCR output model for the 12 evaluated railways, where it was possible to identify three efficient railways: Estrada de Ferro Carajás (EFC), Fortescue (FMG), and Mount Newman (NEWM).

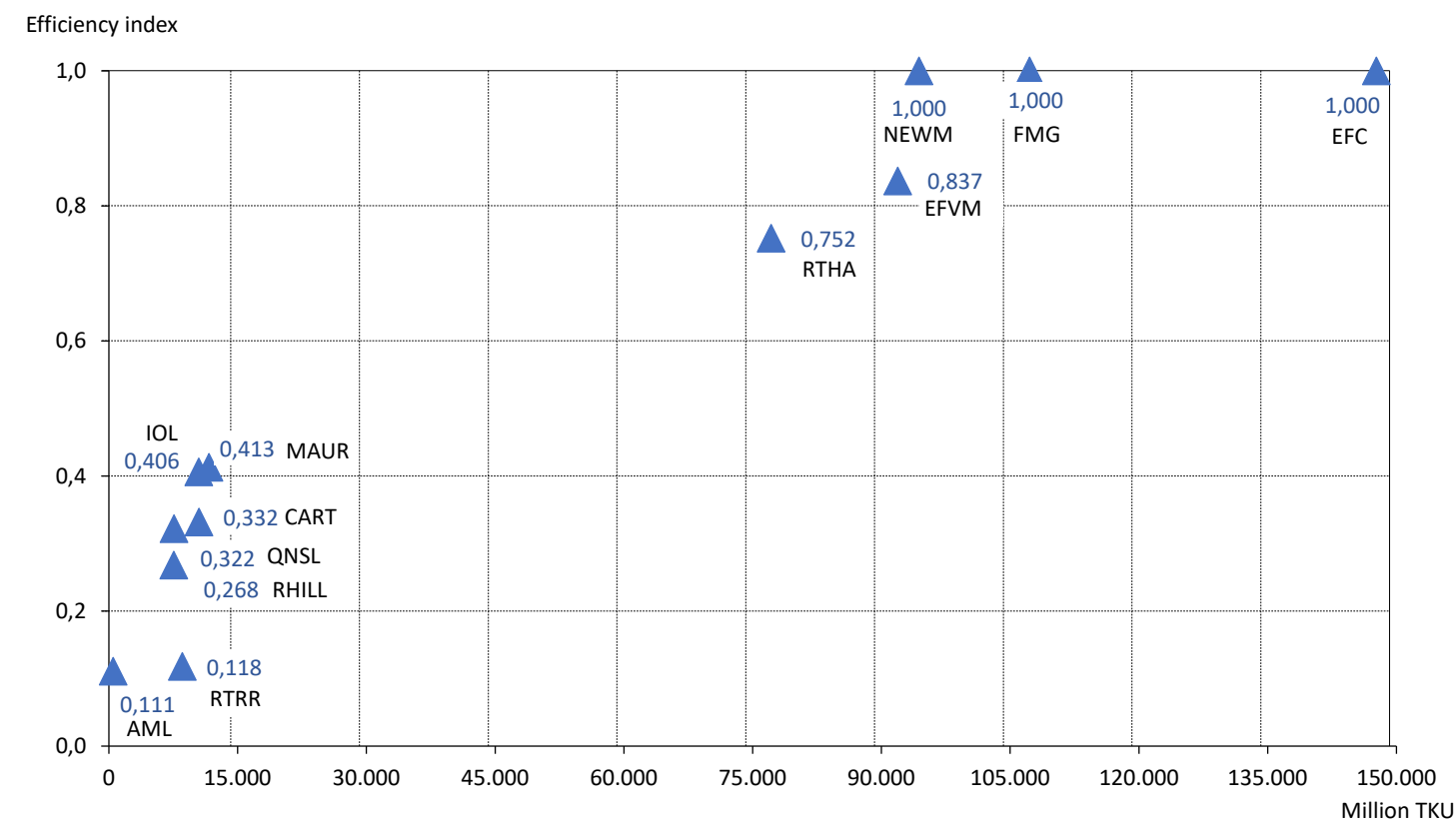

Figure 3. Graphic result of the CCR output model. 
Targets for the DMU output variable TKU that did not reach an efficiency index of one help companies evaluate measures taken in rail transport to improve efficiency. Besides, it presents DMUs that have clearances in one or more input variables. For the VAG variable, no DMU showed clearance, demonstrating that this input variable is adequate to the TKU output variable. For the TTP and CGE variables, the model indicated adjustments.

Table 4 shows the target and clearance of the input variables TTP and CGE for each DMU. For the TTP variable, six DMU have clearance in the number of wagons that are part of the type of train that is most prevalent on the railroad. At EFVM, the adjustment is minor, with the proposal to reduce five wagons. On the other railways, the reduction proposal is more significant, which varies from 57 to 198 wagons in the composition of a train. Reducing the number of wagons on the most predominant type of train (TTP) does not appear to be a good option, given the loss of scale in transportation on railways already planned for the existing type of train.

For the input variable CGE, eight DMUs have clearance requiring adjustments ranging from 5.3 to 33.8 ton/axis. The reduction in axle load (CGE) can be achieved by decreasing the amount of product transported by wagon, but it does not make sense to transport several wagons without using their maximum capacity.

Table 4. Target and clearance of variables TTP, CGE, and TKU.

\begin{tabular}{ccccccccccc}
\hline \multirow{2}{*}{ DMU } & \multirow{2}{*}{$\begin{array}{c}\text { Efficiency } \\
\text { index }\end{array}$} & \multicolumn{3}{c}{ Observed values } & \multicolumn{3}{c}{ Target values } & \multicolumn{2}{c}{ Clearance values } & Increment \\
\cline { 3 - 11 } & & TTP & CGE $^{2}$ & TKU $^{3}$ & TTP $^{1}$ & CGE $^{2}$ & TKU $^{3}$ & TTP $^{1}$ & CGE $^{2}$ & TKU $^{3}$ \\
\hline EFC & 1.000 & 330 & 32.5 & 147,666 & 330 & 32.5 & - & - & - & - \\
FMG & 1.000 & 250 & 42.0 & 107,260 & 250 & 42.0 & - & - & - & - \\
NEWM & 1.000 & 268 & 37.5 & 94,382 & 268 & 37.5 & - & - & - & - \\
EFVM & 0.837 & 252 & 27.5 & 91,917 & 247 & 27.5 & 109,768 & 5 & - & 17,851 \\
RTHA & 0.752 & 236 & 40.0 & 77,160 & 236 & 34.7 & 102,577 & - & 5.3 & 25,417 \\
MAUR & 0.413 & 210 & 30.0 & 11,686 & 80 & 11.3 & 28,315 & 130 & 18.7 & 16,628 \\
IOL & 0.406 & 68 & 32.5 & 10,491 & 68 & 10.2 & 25,830 & - & 22.3 & 15,339 \\
CART & 0.332 & 200 & 30.0 & 10,500 & 90 & 12.6 & 31,618 & 110 & 17.4 & 21,118 \\
QNSL & 0.322 & 265 & 36.0 & 7,608 & 67 & 9.4 & 23,596 & 198 & 26.6 & 15,988 \\
RHILL & 0.268 & 232 & 45.0 & 7,568 & 80 & 11.2 & 28,220 & 152 & 33.8 & 20,652 \\
RTRR & 0.118 & 167 & 40.0 & 8,570 & 167 & 25.3 & 72,383 & - & 14.7 & 63,812 \\
AML & 0.111 & 70 & 30.0 & 510 & 13 & 1.8 & 4,601 & 57 & 28.2 & 4,091 \\
\hline
\end{tabular}

Note. Source: Prepared by the authors. Units of measurement: ${ }^{1}$ number of wagons per train; ${ }^{2}$ tons per axle (ton/axle); ${ }^{3}$ million tons per kilometer (million ton.km).

Table 4 also shows the target and the necessary increment in the TKU output variable so that DMUs reach the efficiency index equal to one. It is observed in the results that nine DMUs need adjustments in the TKU. An increase of $19 \%$ in the TKU of the EFVM railroad and of $33 \%$ in the TKU of the RTHA railroad is proposed. The RTRR, RHILL, QNSL, CART, AML, IOL, and MAUR railways need to increase more than $140 \%$ of their TKU to be efficient.

Regarding data analysis, the flow proposed in Figure 4 was used, highlighting the points that need to be investigated before making a decision, considering the increase in the output variable and/or eliminating the slack values of input variables.
Although the results indicate the need to increase TKU for non-efficient DMUs, it is necessary to assess whether companies are able and/or interested in investing to increase production and whether mines/pelletizers can expand production. There may also be mines with growing production, ramp up projects, and thus the railroad already has wagons, locomotives, and transport capacity, but as the mine is not producing at full potential, the railroad operates below installed capacity.

Another cause may be exhausting mines, with decreasing volumes, leading the railway to have excess wagons. However, the reduction of the fleet would not be feasible if companies have projects to replace this volume, which would lead to the use of these assets in the future. 


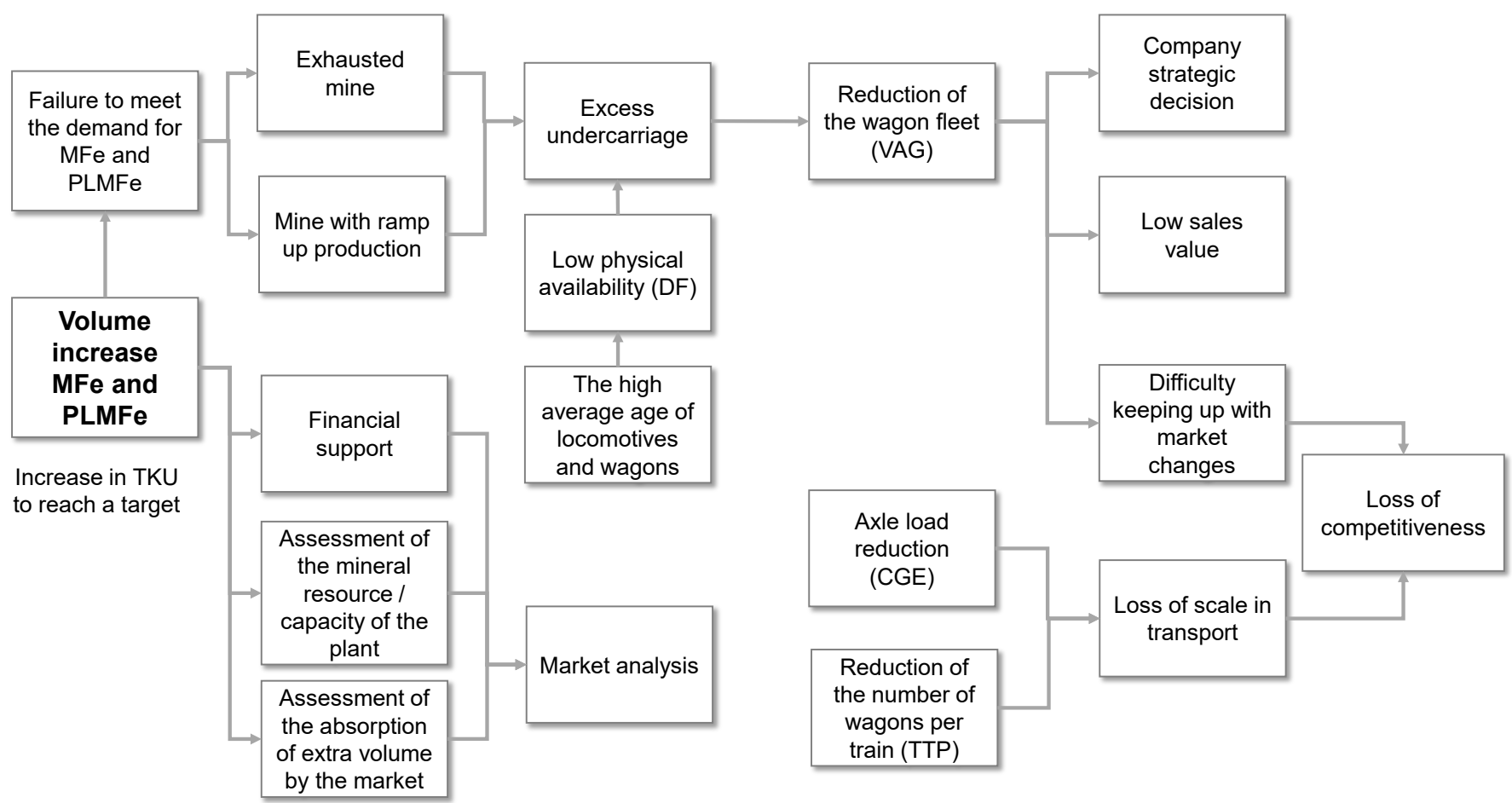

Figure 4. Flow for analyzing the results of the Frontier Analyst software.

The reduction in wagons can leave the company vulnerable in the event of a change in the MFe and PLMFe market. Divestment in the railroad could result in a loss of competitiveness, in addition to the low value that would be obtained from the sale of these wagons. Nevertheless, this reduction may be a strategic decision, which only the top management of the companies can take.
Table 5 presents a summary of the percentage increase in TKU, the volume of MFe/PLMFe that each DMU handled (TUU) in 2016, and the amount needed to increase production to achieve an efficiency ratio of one. The following analyses were performed based on Tables 1 , 2 , and 4 .

Table 5. Summary of analysis of suggestions on increasing the volume handled.

\begin{tabular}{|c|c|c|c|c|}
\hline DMU & $\begin{array}{l}\text { Increase in TKU } \\
(\%)\end{array}$ & $\begin{array}{l}\text { Volume in the year } \\
2016^{1}\end{array}$ & $\begin{array}{l}\text { The volume required } \\
\text { to achieve efficiency }{ }^{1}\end{array}$ & Analysis of suggestions on productive capacity \\
\hline EFC & - & 148 & - & Increasing production of the $S 11 \mathrm{D}$ project \\
\hline FMG & - & 173 & - & No production growth plans \\
\hline NEWM & - & 222 & - & Has an expansion project to $290 \mathrm{Mta}$ \\
\hline EFVM & $19 \%$ & 103 & 123 & No production growth plans \\
\hline RTHA & $33 \%$ & 235 & 313 & No production growth plans \\
\hline MAUR & $142 \%$ & 17 & 40 & No production growth plans \\
\hline IOL & $146 \%$ & 27 & 66 & No production growth plans \\
\hline CART & $201 \%$ & 25 & 76 & No production growth plans \\
\hline QNSL & $210 \%$ & 18 & 56 & No production growth plans \\
\hline RHILL & $273 \%$ & 22 & 82 & Increasing production with stability in 2018 of $55 \mathrm{Mta}$ \\
\hline RTRR & $745 \%$ & 35 & 299 & No production growth plans \\
\hline AML & $802 \%$ & 2 & 19 & Has an expansion project to $15 \mathrm{Mta}$ \\
\hline
\end{tabular}

Note. Source: Prepared by the authors. Unit of measure: ${ }^{1}$ million tons. 
In most cases, the increase in TKU needed to achieve efficiency would be difficult to obtain since most companies keep their MFe/PLMFe production stable, encouraged by market uncertainty and significant fluctuations in the price of MFe. On the other hand, in the event of a change in the world scenario and increased demand, companies would need to increase their production and adapt the railroad for the products' disposal.

Several companies have no plans to grow, but they can increase production at any time due to the increase in global demand. However, the railway has a very flexible operation and does not absorb adjustments in a short period. As the asset fleet is very complex to be changed, since the residual value of wagons and locomotives is negligible for sale, almost sold as scrap, it is challenging to be purchased in the event of an upturn in world demand. Thus, we understand that the company's focus is to grow and serve the market and not to languish because it does not have assets that respond to demand.

EFVM is a railroad with a highly branched mesh and is the only metric-gauge railroad, which implies limitation of track capacity and smaller wagons than other MFe and PLMFe railways, leading to less transport capacity for the railroad. For this railroad to become efficient, the CCR output model suggests an increase of $19 \%$ in its TKU, from 91,917 million ton. $\mathrm{km}$ to 109,768 million ton. $\mathrm{km}$. This percentage represents an increase from 103 Mta to 120 Mta. Despite having productive capacity, Vale announced to the market that it would not make investments in the Southeast System, which is served by the EFVM railroad, focusing its efforts on expanding the production of the MFe S11D mine in the Northern System, which is served by the EFC railroad.

The EFC is the only railway among the DMUs studied with a $1.60 \mathrm{~m}$ gauge and has the most extensive train, with 330 wagons. It is considered by the DEA method as efficient by default because it has the highest TKU value in the sample and does not require any adjustment. The EFC has the input variables consistent with the volume of MFe transported. Vale Norte has increased production of $\mathrm{MFe}$ in the long term, coming from the S11D project.

NEWM is BHP's only active Australian railroad following the shutdown of the Yarrie mine in 2014, which was served by the Goldsworthy railroad. It has a standard gauge of $1.435 \mathrm{~m}$ and serves four mine complexes, transporting MFe. This railroad was also considered efficient, not needing adjustments in its input and output variables. BHP has increased the production of $\mathrm{MFe}$ in the long run and the balance between inputs and output, which may maintain it as an efficient railroad in the coming years.
Rio Tinto has two logistical corridors, comprising the RTRR and RTHA railways, both of which are standard gauge. The result suggests a significant increase in the amount of TKU on the RTRR railroad, from 8,570 million ton.km to 72,383 million ton. $\mathrm{km}$. Regarding the RTHA railroad, the change is minor. The result suggests that the TKU is increased from 77,146 million ton. $\mathrm{km}$ to 102,577 million ton. $\mathrm{km}$, representing an increase of $33 \%$. Currently, the increase in TKU is not favorable because Rio Tinto has in its long-term planning a stable production of MFe until 2025, considering that its projects are to supply the lost volume with the exhaustion of some mines. However, it maintains a quantity of undercarriage higher than necessary because it has other expansion projects temporarily suspended, awaiting an increasing resumption of demand for MFe. For the RTRR railroad, the increase in TKU is very high, which would hardly be met by the productive capacity of the Robe River Complex. A more careful assessment is necessary to ensure that the input variables are oversized concerning the volume expected in the new projects.

FMG is a unique railway to MFe with standard gauge and 42 tons per axle. It is a new, well-structured railway, with track capacity prepared for future expansions. Its type train has the largest capacity, considering the research sample, with 37,000 tons and a train composition similar to other Australian railways. It was considered by the model as efficient, with no adjustments to be made.

RHILL is the most recent large-scale Australian railroad built, which went into operation in 2015, with 45 tons per axle, standard gauge, and MFe handling in the Pilbara region. Its efficiency index is 0.268 and demands growth in TKU, in which an increase of $273 \%$ is suggested, going from 8,570 million ton. $\mathrm{km}$ to 28,220 million ton.km. This railroad was planned for a future MFe production that was not fully reached until 2016. The Roy Hill railroad had an increasing MFe production until 2018, when it reached its stability with $55 \mathrm{Mta}$. As it is a new and expanding railway, it is interesting to have a new evaluation starting in 2019 to verify its performance.

The IOC's QNSL railway, standard gauge, transported PLMFe and had a low-efficiency index equal to 0.322 . The results point to a need to increase the TKU from 7,608 million ton.km to 23,596 million ton. $\mathrm{km}$, representing $210 \%$. IOC's PLMFe production unit is not prepared for such an expressive increase, and its planning shows stability in long-term production. The standard gauge Arcelor Mittal CART, which carries MFe and PLMFe, also had a low-efficiency index equal to 0.332 . It would be necessary to increase the TKU by $201 \%$, from 10,500 million ton. $\mathrm{km}$ to 31,618 million ton. $\mathrm{km}$, to become efficient. It is not very easy for railways of the size 
of CART and QNSL to significantly increase the volume transported because they do not have growth plans in the coming years.

The standard gauge Arcelor Mittal AML railroad carries MFe in Liberia. It is a tiny railway, with operations resumed in 2015 and handling 510 million ton.km of MFe. Its fleet is small, and its train consists of only one locomotive and seventy wagons; hence, the Arcelor Mittal AML railroad cannot be a reference for other railways. Arcelor Mittal of Liberia presented the investment in an expansion project that will increase its production to 15 Mta. This growth will partially meet the increase in TKU on the AML railroad, which requires $19 \mathrm{Mt}$ to become efficient.

The IOL railroad has a standard gauge and handles MFe and PLMFe for export. To become efficient, the IOL needs to adjust the TKU variable, with a $146 \%$ increase, from 10,491 million ton. $\mathrm{km}$ to 25,830 million ton. $\mathrm{km}$. In its long-term planning, the company demonstrates stable production, making it challenging to meet this increase in TKU.

SNIM's MAUR railroad, with an efficiency index of 0.413 , needs a significant adjustment in the amount of TKU, going from 11.686 million ton.km to 28.315 million ton.km, which characterizes an increase of $142 \%$. SNIM also presented a long-term stability plan, preventing such a significant increase.

In general, this study allows managers to know the necessary operational adjustments concerning the number of wagons per train and load per axle and the acquisition of wagons that will allow their growth to meet the demand for MFe and PLMFe.

\section{CONCLUSIONS}

This article proposed the use of the DEA CCR output method to measure and compare the efficiency of railways specialized in the transportation of MFe and PLMFe, which are part of the heritage of mining companies and pellet plants and, therefore, do not charge freight for the transportation of MFe and PLMFe.

Three input variables were defined using the initial combinatorial multicriteria method, namely: (a) the number of wagons in operation (VAG); (b) the axle load of the wagon (CGE); and (c) the number of wagons of the most predominant type of train (TTP). The output variable was the useful tone-kilometer (TKU). Finally, tobit regression was used as a validation strategy for the DEA model.
From the survey carried out of the railways that transport MFe and PLMFe in the world scenario of the year 2016, it was discovered that 12 railroads are the patrimony of mining companies and/or pelletizing plants and do not charge freight from their proprietary companies. Of these 12 railways, it was noticed that three are considered to be efficient, namely: (a) Estrada de Ferro Carajás (EFC); (b) Mount Newman (NEWM); and (c) Fortescue (FMG). The other railways need adjustments to become efficient, and proposals are evaluated about the market in which they are inserted.

In general, due to the proportionality between the input and output variables, i.e., constant return of scale, the CCR output model was considered an excellent method to evaluate the efficiency of the railways specialized in transporting MFE and PLMFe, as it determined the efficiency of each DMU, suggesting the necessary increase in TKU for the railroads to reach an efficiency index equal to one and possible adjustments to the input variables. However, if another set of variables is used that demonstrate convex (increasing scale return) or concave (decreasing scale return) combinations, it is interesting to use the BCC model, considering that the results are conditioned to a specific set of values for it is a relative efficiency.

Considering that the MFe market is dynamic, companies will be able to use the results of this article to guide future improvements in the case of expansion of their production, making their railroads more efficient or remaining on the frontier of efficiency.

Finally, this work has some limitations for restricting the scope to the year 2016. It presents itself as an opportunity for future studies to evaluate the fifth event that changed the MFe and PLMFe market dynamics and unbalanced supply and demand: the Brumadinho reject dam's rupture occurred in 2019. It is also suggested to apply the DEA methodology to ports, the following link in the MFe and PLMFe logistics chain destined for the customer.

The continuity of this and other works may provide indications for $\mathrm{MFe}$ and PLMFe companies that may suggest how to increase their efficiency in the links of the logistics chain, reducing costs and increasing the profit margin.

\section{ACKNOWLEDGEMENTS}

The authors thank the Federal Institute of Education, Science and Technology of Espírito Santo (Ifes) for funding the translation of this paper. 


\section{REFERENCES}

Asmild, M., Holvad, T., Hougaard, J. L., \& Kronborg, D. (2009). Railway reforms: Do they influence operating efficiency? Transportation, 36(5), 617-638. https://doi.org/10.1007/s11116-009-9216-x

Banker, R. D., Charnes, A., Cooper, W. W., Swarts, J., \& Thomas, D. (1989). An introduction to data envelopment analysis with some of its models and their uses. In P. A. Copley (Ed.), Research in governmental and nonprofit accounting (Vol. 5, pp. 125-163). Greenwich, CT: JAI Press.

Bogetoft, P., \& Otto, L. (2011). Benchmarking with DEA, SFA, and R (Vol. 157). New York: Springer-Verlag.

Caldas, M.A.F., Gabriele, P.D., Carvalhal, R. L., \& Ramos, T. G. (2012, September). A eficiência do transporte ferroviário de cargas: Uma análise do Brasil e dos Estados Unidos. Proceedings of Congreso Latino Ibero-Americano de Investigación Operativa e Simpósio Brasileiro de Pesquisa Operacional (CLAIO$S B P O)$, Rio de Janeiro, RJ, Brazil, 16. Retrieved from http://www.din.uem.br/sbpo/sbpo2012/pdf/arq0333.pdf

Cantos, P., Pastor, J. M., \& Serrano, L. (2012). Evaluating European railway deregulation using different approaches. Transport Policy, 24, 67-72. https://doi.org/10.1016/j.tranpol.2012.07.008

Charnes, A., Cooper, W. W., \& Rhodes, E. (1978). Measuring the efficiency of decision making units. European Journal of Operational Research, 2(6), 429-444. https://doi.org/10.1016/0377-2217(78)90138-8

Chernick M. R. (2008) Bootstrap methods: A guide for practitioners and researchers. Hoboken, NJ: Wiley.

Cinca, C. S., Molinero, C. M., \& Callén, Y. F. (2016). Input and output search in DEA: The case of financial institutions. In S.-N Hwang \& H.-S. Lee (Eds.), Handbook of operations analytics using data envelopment analysis (pp. 51-87). Boston: Springer.

Garside, M. (2020). Iron ore - statistics \& facts. Statista. Retrieved from https://www.statista.com/topics/1919/iron-ore/

Gujarati, D. N. (2000). Econometria básica. São Paulo, SP: Makron Books.

Kutlar, A., Kabasakal, A., \& Sarikaya, M. (2013). Determination of the efficiency of the world railway companies by method of DEA and comparison of their efficiency by Tobit analysis. Quality \& Quantity, 47(6), 3575-3602. https://doi.org/10.1007/s11135-012-9741-0

Lin, L. C., \& Tseng, C. C. (2007). Operational performance evaluation of major container ports in the Asia-Pacific region. Maritime Policy \& Management, 34(6), 535-551. https://doi.org/10.1080/03088830701695248

Marchetti, D., \& Wanke, P. (2017). Brazil's rail freight transport: Efficiency analysis using two-stage DEA and cluster-driven public policies. Socio-Economic Planning Sciences, 59, 2642. https://doi.org/10.1016/j.seps.2016.10.005

Mello, J. D. S., Gomes, E. G., Meza, L. A., \& Lins, M. E. (2004). Selección de variables para el incremento del poder de discriminación de los modelos DEA. Revista de la Escuela de Perfeccionamiento En Investigación Operativa, (24), 4052. Retrieved from https://www.alice.cnptia.embrapa.br/ bitstream/doc/17494/1/1805.pdf

Merkert, R., Smith, A. S. J., \& Nash, C. A. (2010). Benchmarking of train operating firms - a transaction cost efficiency analysis. Transportation Planning and Technology, 33(1), 35-53. https://doi.org/10.1080/03081060903429330

Miles, J., \& Shevlin, M. (2001). Applying regression and correlation: A guide for students and researchers. London: Sage.

Motta, G. D. S. (2017). Como escrever um bom artigo tecnológico? Revista de Administração Contemporânea, 21(5), 4-8. https:// doi.org/10.1590/1982-7849rac2017170258

Pereira, M. A., Rosa, F. S. da, \& Lunkes, R. J. (2015). Análise da eficiência ferroviária no Brasil nos anos entre 2009 a 2013. Transportes, 23(3), 56-63. https://doi.org/10.14295/transportes.v23i3.909

Reis, J. C., Sacramento, K. T., Mello, J. C. C. B. S. de, \& Meza, L. A. (2017). Avaliação de eficiência das ferrovias brasileiras: Uma aplicação do método multicritério para seleção de variáveis em DEA e representaçáo gráfica bidimensional. Revista Espacios, 38(14), 16-26. Retrieved from https:// www.revistaespacios.com/a17v38n14/17381416.html

Sharma, M. G., Debnath, R. M., Oloruntoba, R., \& Sharma, S. M. (2016). Benchmarking of rail transport service performance through DEA for Indian railways. The International Journal of Logistics Management, 27(3), 629-649. Retrieved from https://www.emerald.com/insight/content/doi/10.1108/ IJLM-08-2014-0122/full/html?fullSc=1

Senra, L. F. A. C., Nanci, L. C., Mello, J. C. C. B. S. de., \& Meza, L. A. (2007). Estudo sobre métodos de seleção de variáveis em DEA. Pesquisa Operacional, 27(2), 191-207. https://doi.org/10.1590/S0101-74382007000200001

Silva, F. G. F., Oliveira, R. L. M., \& Marinov, M. (2020). An analysis of the effects on rail operational efficiency due to a merger between Brazilian rail companies: The case of RUMO-ALL. Sustainability, 12(12), 4827. https://doi.org/10.3390/su12124827

Simar L. \& Wilson, P. W. (1998) Sensitivity analysis of efficiency scores: How to bootstrap in nonparametric frontier models. Management Science, 44(1), 49-61. Retrieved from http:// www.jstor.org/stable/2634426

Wanke, P., Chen, Z., Liu, W., Antunes, J. J., \& Azad, M. A. K. (2018). Investigating the drivers of railway performance: Evidence from selected Asian countries. Habitat International, 80, 4969. https://doi.org/10.1016/j.habitatint.2018.08.004

Yu, M.-M. (2008). Assessing the technical efficiency, service effectiveness, and technical effectiveness of the world's railways through NDEA analysis. Transportation Research Part A: Policy and Practice, 42(10), 1283-1294. https://doi.org/10.1016/j.tra.2008.03.014

Zhou, H., \& Hu, H. (2017). Sustainability evaluation of railways in China using a two-stage network DEA model with undesirable outputs and shared resources. Sustainability, 9(1), 150. https://doi.org/10.3390/su9010150 


\section{Authorship}

\section{Renata Guimarães de Oliveira Fontan}

Universidade Federal do Espírito Santo, Programa de Pósgraduação em Engenharia Civil

Av. Fernando Ferrari, n 514, Goiabeiras, 29075-910, Vitória, ES, Brazil.

E-mail address: regol.fontan@gmail.com

(D) https://orcid.org/0000-0002-2516-3514

\section{Rodrigo Alvarenga Rosa}

Universidade Federal do Espírito Santo, Programa de Pósgraduação em Engenharia Civil

Av. Fernando Ferrari, no 514, Goiabeiras, 29075-910, Vitória, ES, Brazil.

E-mail address: rodrigoalvarengarosa@gmail.com

(D) https://orcid.org/0000-0003-0841-514X

\section{Adonai José Lacruz*}

Universidade Federal do Espírito Santo, Programa de Pósgraduação em Administração

Av. Fernando Ferrari, no 514, Goiabeiras, 29075-910, Vitória, ES, Brazil.

Instituto Federal do Espírito Santo

Rod. BR 101, Km 12, s/n, Universal, 29135-000, Viana, ES, Brazil.

E-mail address: adonai.lacruz@ifes.edu.br

(D) https://orcid.org/0000-0003-1575-3788

* Corresponding Author

\section{Funding}

The authors reported that there is no financial support for the research in this article.

\section{Conflict of Interests}

The authors have stated that there is no conflict of interest.

\section{Plagiarism Check}

The RAC maintains the practice of submitting all documents approved for publication to the plagiarism check, using specific tools, e.g.: iThenticate.

\section{Authors' Contributions}

$1^{\text {st }}$ author: conceptualization (lead); data curation (lead); formal analysis (lead); methodology (lead); writing-original draft (lead); writing-review \& editing (equal).

$2^{\text {nd }}$ author: conceptualization (supporting); formal analysis (supporting); methodology (supporting); supervision (lead); writing-original draft (supporting); writing-review \& editing (equal).

$3^{\text {rd }}$ author: methodology (supporting); supervision (supporting); writing-original draft (supporting); writingreview \& editing (equal).

\section{Copyrights}

RAC owns the copyright to this content.

\section{Peer Review Method}

This content was evaluated using the double-blind peer review process. The disclosure of the reviewers' information on the first page, as well as the Peer Review Report, is made only after concluding the evaluation process, and with the voluntary consent of the respective reviewers and authors.

\section{Data Availability}

All data and materials have been made publicly available through the Harvard Dataverse platform and can be accessed at:

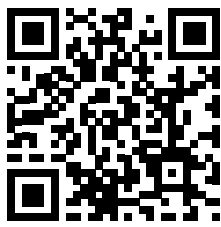

Renata Guimarães de Oliveira Fontan; Rodrigo de Alvarenga Rosa; Adonai Lacruz, 2021, "Replication Data for: The efficiency of railways specialized in transporting iron ore and pellets", Harvard Dataverse, V1. https://doi.org/10.7910/DVN/Y8CS9Q

RAC encourages data sharing but, in compliance with ethical principles, it does not demand the disclosure of any means of identifying research subjects, preserving the privacy of research subjects. The practice of open data is to enable the reproducibility of results, and to ensure the unrestricted transparency of the results of the published research, without requiring the identity of research subjects. 